\title{
EFFECT OF ELISA KIT MANUFACTURING PROCESS AND INCUBATION TIME ON PROGESTERONE CONCENTRATION MEASURED IN DOG SERUM FOR OVULATION DIAGNOSIS - SHORT COMMUNICATION
}

\author{
Julianna THURÓCZY ${ }^{1 *}$, Jenő REICZIGEL ${ }^{2}$ and Lajos BALOGH ${ }^{3}$ \\ ${ }^{1}$ Department and Clinic of Reproduction and ${ }^{2}$ Department of Biomathematics and \\ Informatics, University of Veterinary Medicine, István u. 2, H-1078 Budapest, Hungary; \\ ${ }^{3}$ National Research Directorate for Radiobiology and Radiohygiene, \\ National Public Health Centre, Budapest, Hungary
}

(Received 8 December 2015; accepted 4 May 2016)

\begin{abstract}
Twenty-two serum samples of healthy bitches were tested with the frozen and lyophilised version of the same ELISA kit (Quanticheck, Faculty of Veterinary Science, Budapest, Hungary). Samples were chosen on the basis of their progesterone $\left(\mathrm{P}_{4}\right)$ concentrations, which were between 1.00 and $20.00 \mathrm{ng} / \mathrm{mL}$. As it is well known, this range has the highest clinical relevance in ovulation diagnosis. Both types of microplates were read at 15 -min intervals from the 15th until the 90th minute (min) of incubation, and the results were compared with those of frozen plates at $60 \mathrm{~min}$ of incubation as 100 percent. Lyophilised microplates gave on average 18 percent higher results than the frozen version at equal incubation times. The highest difference between lyophilised and frozen samples was observed at 45 and $60 \mathrm{~min}$ of incubation. Ninety-four percent of the reaction in the frozen microplate occurred in the first $15 \mathrm{~min}$, and during the subsequent 30 min the reaction seemingly stopped. After the 45 th min of incubation, this 94 percent increased to 108 percent in the subsequent $30 \mathrm{~min}$, which remained the final approximate result at the end of the $90 \mathrm{~min}$ of incubation. In contrast to the frozen microplate, the measured concentration increased continuously in the lyophilised version and reached the highest level at the 60th min. The results of the lyophilised microplate reached the same level at $30 \mathrm{~min}$ of incubation as those of the frozen version at $60 \mathrm{~min}$. In conclusion, a mechanical increase or decrease of the incubation time does not generate a linear change in the test results. This study demonstrated that the results of a series of samples collected from the same bitch cannot be compared if they are measured with different laboratory methods or different ELISA kits.
\end{abstract}

Key words: Progesterone, ELISA, accuracy, incubation time

Determination of the optimal breeding time plays a key role in reducing the expenses and increasing breeding success in the bitch. Serum or plasma pro-

"Corresponding author; E-mail: thuroczy.julianna@univet.hu; Phone: 0036 (1) 478-4200; Fax: 0036 (1) 478-4207 
gesterone $\left(\mathrm{P}_{4}\right)$ concentration has a predictive value in the diagnosis of the estimated time of ovulation. The clinically relevant progesterone concentration varies widely, depending on the period of the oestrous cycle (Concannon, 2011).

Radioimmunoassay (RIA), which had been the only available method twenty years ago, has by now been replaced by enzyme immunoassay (ELISA) in the everyday practice due to its shorter measurement times and use of nonradioactive reagents (Munro and Stabenfeldt, 1984). The commercial availability of inexpensive, precise and accurate quantitative kits validated for canine samples displaces the previously used qualitative and semi-quantitative ELISA kits. Such kits are widely used not only in laboratories but also in the clinical practice; however, they are sensitive to the conditions of measurement.

The theoretical background of enzyme immunoassays for quantitative hormone determination is based on competitive binding of the enzyme-labelled hormone and the measurable component of the sample. The non-labelled hormone molecules reduce the number of free binding sites on antibodies and decrease their availability to the labelled hormone. At equilibrium, the dissolved mixture of non-bound hormone and non-bound enzyme-conjugated hormone is eliminated from the microplates and the reaction is quantified by the determination of the amount of labelled hormone (Crowther, 1995).

The final result of the ELISA is influenced by numerous factors. Besides biological factors and sample management, the assay method, the storage conditions and handling also influence the final concentrations measured (Molnár et al., 1984; Navarro et al., 1990; Hock et al., 1999; Thuróczy et al., 2003; Volkmann, 2006; Chapwanya et al., 2008; Tahir et al., 2013; Schumacher et al., 2014).

Although the production of ELISA kits is a multistep procedure which directly influences the final quality and the recommended instructions for use, the ultimate users are not fully aware of the methods employed (Henning and Nielsen, 1987; Sibley et al., 1993; Hock et al., 1999).

As the assay procedure is properly described, its ultimate use does not require an expert laboratory specialist. The decrease or increase of the incubation time should raise the suspicion of automatic linear changes in the final results. Although the alteration of incubation time is part of the assay validation protocols, clinicians are not aware of these results and an inexperienced ELISA user should suspect a linear correlation between the result and the incubation time. The applied test is widely used in small animal practice in Hungary and it is on the market in some other countries as well. The aim of this study was to illustrate the effect of incubation time on the measured progesterone results and demonstrate that the results coming from two differently produced, although apparently similar kits may be different. The latter phenomenon raises difficulties in comparing results given by two or more different laboratories in a single examined heat of the same bitch. 


\section{Materials and methods}

Progesterone was determined with two differently manufactured versions [lyophilised (L) and frozen (F)] of the same ELISA kit (Quanticheck, Faculty of Veterinary Science, Budapest, Hungary).

Kit $\mathrm{L}$ includes a microplate coated with monoclonal antibody against $\mathrm{P}_{4}$, which is lyophilised at the end of the process and kept at room temperature in a hermetically closed foil until the measurements. The intra-assay variability is $3.44 \%$, the inter-assay coefficient is $5.25 \%$, and the sensitivity of the assay is $0.5 \mathrm{ng} / \mathrm{mL}$. Kit $\mathrm{F}$ contains anti- $\mathrm{P}_{4}$ monoclonal antibody dissolved in physiological sodium chloride, and the microplates were kept frozen at $-20^{\circ} \mathrm{C}$. The intraassay variability is $5.14 \%$, the inter-assay coefficient is $3.79 \%$, and the sensitivity of the assay is $0.2 \mathrm{ng} / \mathrm{mL}$. The prescribed incubation time of covered strips at room temperature is one hour. Both kits use the same $\mathrm{P}_{4}$ concentrations $(0,1,2$, $5,10,20$ and $40 \mathrm{ng} / \mathrm{mL}$ ) as standards.

Twenty-two serum samples of healthy bitches were compared. The samples were collected from healthy bitches during prooestrus, oestrus or onset of metoestrus as part of the daily clinical service, requested by the owners to predict the optimal time of mating. The samples were selected on the basis of previous results which ranged between 1.00 and $20.00 \mathrm{ng} / \mathrm{mL}$ for $\mathrm{F}$ microplates at $60 \mathrm{~min}$ of incubation time (F60) and stored at $-20^{\circ} \mathrm{C}$ until the assay. The same samples were measured with $\mathrm{F}$ and $\mathrm{L}$ microplates and both types of microplates were read at 15-min intervals from the 15 th until the 90th min of incubation with the $\mathrm{P}_{4}$ conjugate. To decrease the measurement error, the samples were measured parallel with the $\mathrm{L}$ and the $\mathrm{F}$ kit again.

To compare the two ELISA kits and to evaluate the dependence of results on incubation time, linear models were applied using the statistical software $\mathrm{R}$ 3.0.2. Absolute as well as relative (percent) differences were used in the comparisons. The measured values were also compared to the reference value (F60).

\section{Results}

The $\mathrm{P}_{4}$ values obtained at 60 min of incubation by the laboratory using $\mathrm{F}$ microplates ranged between 1.22 and $19.94 \mathrm{ng} / \mathrm{mL}$. The results of any other incubation time were compared with the results obtained on $\mathrm{F}$ microplates at 60 min of incubation (F60) as 100 percent. The mean of the reference F60 group was $6.09 \pm 4.87(\mathrm{SD}) \mathrm{ng} / \mathrm{mL}$. The corresponding results in L microplates (L60) were $7.18 \pm 5.22 \mathrm{ng} / \mathrm{mL}$ with a range of $1.24-22.48 \mathrm{ng} / \mathrm{mL}$. L microplates gave on average 18 percent higher results than $\mathrm{F}$ microplates for equal incubation times. The highest difference between the samples measured on $\mathrm{L}$ and $\mathrm{F}$ microplates was observed at 45 and 60 min of incubation (Fig. 1). 


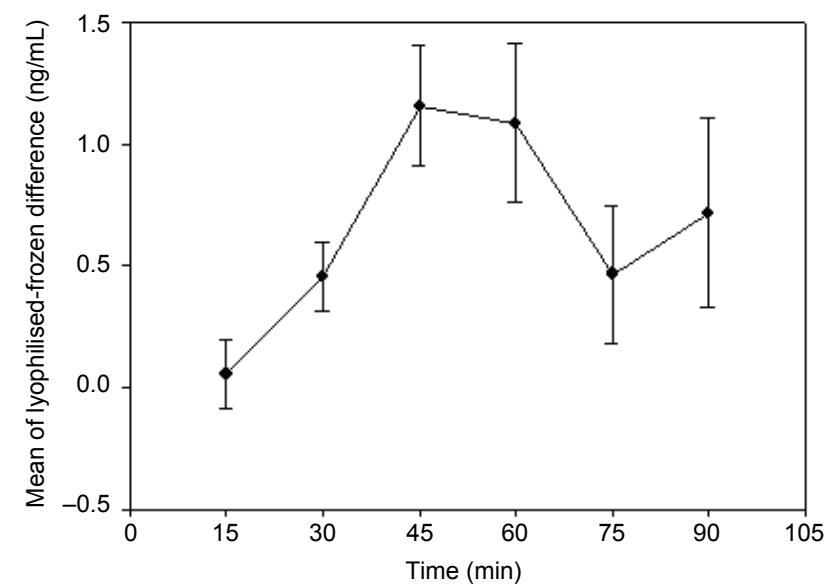

Fig. 1. The widest differences between lyophilised and frozen microplates were measured at the 45 th and 60 th min of incubation. Although the difference in average was the same at the 30th and 75 th $\mathrm{min}$, the values scattered more widely at the 75 th $\mathrm{min}$. Lyophilised microplates gave on average 18 percent higher results than the routinely used laboratory method for equal incubation times

Dependence on incubation time was nearly linear from 45 to $90 \mathrm{~min}$ of incubation time for the F microplates, and from 15 to $60 \mathrm{~min}$ for the $\mathrm{L}$ microplates. Two periods of quick increase were observed in the curve obtained with the $\mathrm{F}$ microplate. Ninety-four percent of the reaction occurred in the first $15 \mathrm{~min}$ and during the subsequent $30 \mathrm{~min}$ the reaction ostensibly stopped. After the 45th min of incubation, the 94 percent increased to 108 percent in $30 \mathrm{~min}$, which was the final approximate result at the end of the examination in the 90th min of incubation. In contrast to the $\mathrm{F}$ microplate, the reaction passed off continuously and reached the highest level at the 60th min on the L microplate. Interestingly, on the $\mathrm{L}$ microplate the results decreased by approximately 2 percent between the 60th and 75th min of incubation and then increased again by the 90th min to 101 percent of the L60 value (Fig. 2).

\section{Discussion}

The ELISA procedure described in this paper is an easy-to-perform test, which is widely used in the everyday clinical reproduction practice for the follow-up of canine prooestrus and oestrus. Ovulation is indicated when serum $\mathrm{P}_{4}$ concentration measured by Quantichek is between 6 and $10 \mathrm{ng} / \mathrm{mL}$.

As demonstrated in Fig. 2, the behaviour of samples differs, depending on the preparation of microplates. A continuous, linear elevation of results is observed until the 60th min of incubation time in the group measured by the L microplate. After that point, this increase does not continue. The physical effects of lyophilisation induce denaturation of antibodies as demonstrated by Hock et al. 
(1999). Denaturation transforms the three-dimensional structure of proteins. This structural transformation leads to the slow saturation of antibody binding sites as demonstrated in Fig. 2. Saturation reaches the maximal level at $60 \mathrm{~min}$ of incubation, and incubation times longer than $60 \mathrm{~min}$ do not influence the amount of $\mathrm{P}_{4}$ molecules bound.

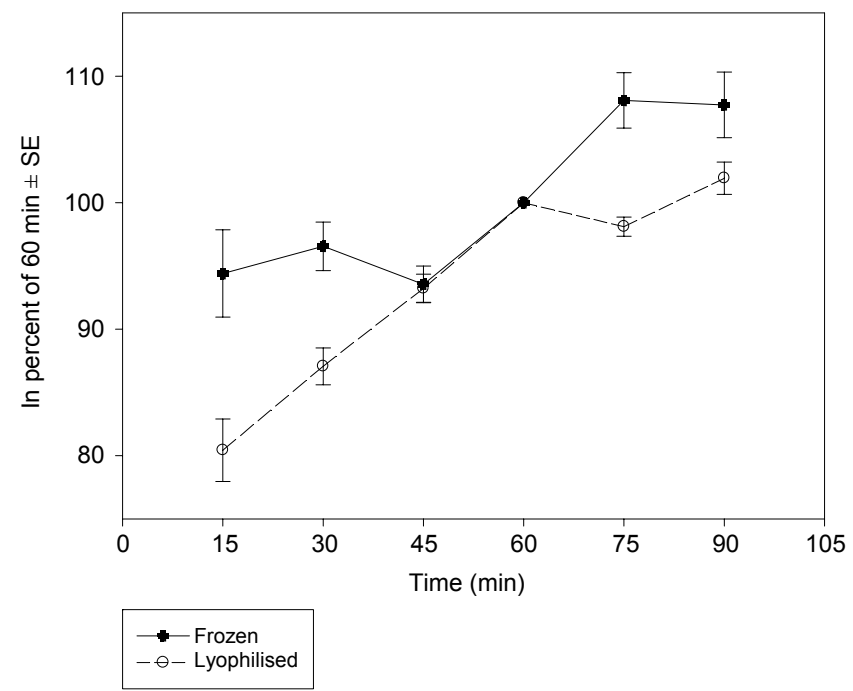

Fig. 2. Ninety-four percent of reaction in frozen microplate occurred in the first 15 min, and during the subsequent $30 \mathrm{~min}$ the reaction ostensibly stopped. In contrast with the frozen microplate, the reaction passed off continuously and reached the highest level at the 60th min in the lyophilised microplate. The results of lyophilised microplate reached the same level at $30 \mathrm{~min}$ of incubation as the results of frozen microplate at $60 \mathrm{~min}$

In contrast to the $\mathrm{L}$ microplate, the $\mathrm{F}$ microplate quickly binds the same amount of measured samples and enzyme-conjugate solution, which is not affected by the incubation time during the first $45 \mathrm{~min}$. The reaction increases progressively between 45 and 75 min of incubation until the antibodies are saturated. The onset of reaction is quicker on the $\mathrm{F}$ microplate, but the final saturation of antibodies occurs at the 60th min on the L microplate.

The variation of measured values depends more on the manufacturing procedure of the microplate than on a hypothetical linear correlation of incubation time. This observation raises the question of commensurability of results obtained by different laboratories with different ELISA kits. The 18 percent difference between the two types of microplates at the recommended incubation time expands the diagnostic value of vaginal cytology and vaginoscopy in the protocol of ovulation diagnosis. Introduction of a new kit requires the comparison of previously used and newly introduced kits. The manufacturers should notify their commercial partners about any changes in the production procedure as it may 
compromise results gained with their assay systems. The producer of the kits should validate its new procedure to the previous system before commercialisation and adjust the instructions for use accordingly.

In conclusion, our results contradict the hypothesis regarding the existence of a linear correlation between incubation time and the increase of measured hormone concentrations. A mechanical increase or decrease of the incubation time does not generate a linear change in the test results. Although the directions for use recommended by the manufacturer are essential for accurate and precise results, the behaviour of microplates is essentially determined by the manufacturing procedure. This study has demonstrated that the measurement with different laboratory methods or different ELISA kits of samples collected from the same bitch during prooestrus and oestrus could lead to apparently different results. This phenomenon increases the significance of using the same laboratory for the testing of a sample series.

\section{Acknowledgements}

This project was funded by the Nonprofit Research Committee of the Faculty of Veterinary Science, Szent István University, Budapest. This publication was supported by the 11475-4/2016/FEKUT grant of the Hungarian Ministry of Human Resources. Thanks are due to Ms Anna Wölfling for the accurate implementation of sample measurements and to Dr. Jusztina Szilágyi for language correction of the manuscript.

\section{References}

Chapwanya, A., Clegg, T., Stanley, P. and Vaughan, L. (2008): Comparison of the Immulite and RIA assay methods for measuring peripheral blood progesterone levels in Greyhound bitches. Theriogenology 70, 795-799.

Concannon, P. W. (2011): Reproductive cycles of domestic bitch. Anim. Reprod. Sci. 124, 200-210.

Crowther, J. R. (Ed.) (1995): ELISA Theory and Practice. Humana Press Inc., Totowa, New Jersey, USA.

Henning, D. and Nielsen, K. (1987): Peroxidase-labelled monoclonal antibodies for use in enzyme immunoassay. J. Immunoassay 8, 297-307.

Hock, B., Rahman, M., Rauchalles, S., Dankwardt, A., Seifert, M., Haindl, S. and Kramer, K. (1999): Stabilisation of immunoassays and receptor assays. J. Mol. Catal. B: Enzym. 7, 115-124.

Molnár, L., Ács, J., Csernus, V., Solti, L., Varró, R. and Huszenicza, Gy. (1984): Enzyme immunoassay (EIA) of progesterone. Proc. of the Symp. on the Analysis of Steroids, Szeged, Hungary.

Munro, C. and Stabenfeldt, G. (1984): Development of a microtitre microplate enzyme immunoassay for the determination of progesterone. J. Endocrinol. 10, 41-49.

Navarro, H., Zarco, L., Ducoing, A., Flores, G. and Valencia, J. (1990): Effect of time and temperature of incubation of heparinized caprine blood on concentrations of progesterone detected in plasma. Theriogenology 33, 749-755. 
Schumacher, M., Mattern, C., Ghoumari, A., Oudinet, J. P., Liere, P., Labombarda, F., SitrukWare, R., De Nicola, A. F. and Guennoun, R. (2014): Revisiting the roles of progesterone and allopregnanolone in the nervous system: Resurgence of the progesterone receptors. Prog. Neurobiol. 113, 6-39.

Sibley, D. E. T., Ramsay, G., Lubrano, G. J. and Guilbault, G. G. (1993): Stability and reusability of enzyme-linked immunosorbent assay (ELISA) microplates. Anal. Lett. 26, 1623-1634.

Tahir, M. Z., Thoumire, S., Raffaelli, M., Grimard, B., Reynaud, K. and Chastant-Maillard, S. (2013): Effect of blood handling conditions on progesterone assay results obtained by chemiluminescence in the bitch. Domest. Anim. Endocrin. 45, 141-144.

Thuróczy, J., Wölfling, A., Tibold, A., Balogh, L., Jánoki, Gy. A. and Solti, L. (2003): Effect of anticoagulants and sampling time on results of progesterone determination in canine blood samples. Reprod. Domest. Anim. 38, 386-389.

Volkmann, D. H. (2006): The effects of storage time and temperature and anticoagulant on laboratory measurements of canine blood progesterone concentrations. Theriogenology 66, $1583-1586$. 